\section{Behaviour of Halide Ions towards Ghloramine-T in Qualitative Analysis}

Verhalten von Halogenionen gegen Chloramin $\mathbf{T}$ in der qualitativen Analyse

\section{V.R.S. RAO}

Department of Chemistry

Indian Institute of Technology, Madras-36, India

Received August 18, 1970

Chloramine-T is used as a cheap substitute for chlorine water in qualitative analysis. However, the behaviour of halides towards ohloramine-T has not yet been well understood. This might lead to difficulties in qualitative analysis. Hence, a detailed study of the behaviour of halides towards chloramine- $T$ was undertaken and the results are reported in this communication.

F'luoride is inert to chloramine- $T$ in all the media ranging from strongly alkaline to strongly acid medium. Chloride is also inert to chloramine-T in the $\mathrm{pH}$ range of 2-14. However, in strong acid medium, chloride ions are oxidized to chlorine and the evolution of chlorine is observed by the starch-iodide paper turning blue. Iodide is oxidized to iodine in all the media ranging from strongly acid to $\mathrm{pH} 6$, when chloramine- $T$ is in a very slight excess. Iodide is inert to chloramine- $T$ in alkaline medium. In presence of excess of chloramine- $T$, iodide is oxidized to iodate in the $\mathrm{pH}$ range $2.65-5$ and also in sulphuric acid medium. Under these conditions, iodide cannot be detected by the above test. In $2-4 \mathrm{M}$ hydrochloric acid medium iodide is oxidized by chloramine- $T$ to iodine monochloride which can be extracted with organic solvent. The yellow colour of the organic layer indicates the presence of iodine monochloride. Bromide destroys all chloramine-T in the $\mathrm{pH}$ range $2.65-5.0$ by way of free radical reaction and when bromide is in large excess, unstable bromamine- $\mathrm{T}$ is formed. Above $\mathrm{pH} 5$, bromide is not reacted by chloramine-T. In strong acid medium, bromide is oxidized only to bromine.

Hence, it is suggested that the detection of iodide should be carried out only in 2-4 M hydrochloric acid medium and bromide can be tested either in hydrochloric or sulphuric acid medium. Under these conditions excess chloramine- $T$ does not interfere in the test. Chloramine- $T$ solutions of $0.1-0.5^{0} \%$ can be used in place of $1 \%$ solution. This would further cut down the cost of the chemicals used in the qualitative tests.

Dr. V. R. S. Rao

Department of Chemistry

Indian Institute of Technology

Madras-36, India

\section{Triphenylmethane Dyes as Iodometric Indicators}

Triphenylmethanfarbstoffe als jodometrische Indicatoren

N. Venkateswara Rao and V. V. S. Eswara DutT

Chemistry Department, Andhra University, Waltair, India

Received September 7, 1970

During recent times, the use of triphenylmethane dyes, Malachite Green (C.I. No. 42000) (Meditsch [2]) and Basic Blue 11, Basic Blue 15, Basic Blue 20 and Basic Violet 4 (C.I. Nos. 44040, 44085, 42585 and 42600 , respectively) (Brazier and Stephen [1]) as indicators in the iodine-thiosulphate titration has been reported. We have found that Setoglaucine 0 and Setocyanine Supra (C.I. Nos. 42025 and 42140 , respectively), belonging to the same class of dyes, can be satisfactorily employed as indicators in the titration of iodine with thiosulphate and arsenic(III) or vice versa.

Reagents. $0.1 \mathrm{~N}$ solutions of iodine and sodium thiosulphate are prepared and standardised. $0.1 \mathrm{~N}$ solution of arsenic(III) oxide is prepared from E. Merck p.a. sample.

$0.1 \%$ solutions of the dyes Setoglaucine 0 and Setocyanine Supra (obtained from Edward Gurr Ltd., London) are prepared in double distilled water.

All other chemicals used in this investigation are of reagent grade quality.

Procedure. An aliquot volume of the iodine solution is taken into a $250 \mathrm{ml}$ iodine flask and the solution is diluted to $50 \mathrm{ml}$. The solution is then titrated with sodium thiosulphate and when the mixture attains a pale yellow colour, $0.25 \mathrm{ml}$ of $0.1 \%$ indicator solution is added and the titration is continued till the colour changes sharply from emerald green to blue.

The titration can be also carried out using arsenic(III) oxide in place of sodium thiosulphate, in which case, however, about $1 \mathrm{~g}$ of sodium hydrogencarbonate has to be added to the titration mixture, before titration, in order to maintain the $\mathrm{pH}$ of the solution between 5 and 9 .

The titration of $0.01 \mathrm{~N}$ solutions of iodine with $0.01 \mathrm{~N}$ thiosulphate or arsenic(III), using the two indicators has to be done with a waiting of 15 to 20 sec near about the end point. This is perhaps due to the slow liberation of the free 